\title{
El Catecismo de Trento, puesto en la picota
}

\section{LUIS RESINES LLORENTE}

RESUMEN: Siempre se ha tenido el catecismo de Trento como garantía de seguridad doctrinal. Hasta el punto de que bastaba con invocar su texto para que las cabezas se agachasen en un asentimiento más obsequioso que comprobado. Por otra parte, era un texto que recogía una doctrina que se entendía como "inmutable", siendo así que no se contemplaba la evolución homogénea del dogma. El artículo muestra los recelos, las sospechas que ha habido en torno al texto, y las deficiencias inherentes al texto mismo, ordinariamente desconocidas.

PAlabras ClaVe: Catecismo, Trento, dogma, seguridad doctrinal, Inquisición.

ABSTRACT: All around the world, the catechism of Council of Trent has been accepted as a sign of theological and doctrinal security. But not in all matters is as secure as it is intented. There was some doubts, suspicions, and corrections to supply some defects in the text of the Catechism, which are not always known.

KEY wORDS: Catechism, Trent, doctrinal security, Inquisition.

El catecismo examinado en este artículo se ha conocido con varios nombres. Corrientemente estos han sido elevados a la categoría de títulos, valorados desde el punto de vista editorial, aunque en realidad la mayor parte de ellos no fueran propiamente títulos. Lo cual no ha sido obstáculo que impidiera reconocer la obra sin margen de duda. 
Su título oficial, en la primera edición de 1566, es Catechismus ex decreto Concilii Tridentini ad Parochos, Pii Quinti Pont. Max. iussu editus, Roma, Paulo Manuzio, 1566. ( = Catecismo [elaborado] por decreto del Concilio de Trento, editado por mandato de Pío Quinto, Pontífice Máximo). Se le conoce por el origen del que procede: «Catecismo de Trento»; o por el lugar de edición primitiva, así como de la sede de donde dimana: «Catecismo romano». También es designado por el papa que ordenó su promulgación: «Catecismo de Pío V». Otra variante se fija en los destinatarios directos para los que estaba redactado: «Catecismo para los párrocos». Nunca ha habido una denominación que se impusiera definitivamente a las otras, y todas lo designan por igual, al subrayar uno u otro aspecto. Pero resulta evidente que, con excepción de la última de las expresiones consignadas, las otras tres subrayan de forma subliminal el principio de autoridad que encierran veladamente: el mismísimo Concilio; la garantía que ofrecía la sede romana; o el prestigio supremo del pontífice que lo promulgó. Por más que quiera diluirse el énfasis de estas expresiones, es claro que cualquiera de ellas evocaba una estima que rozaba los límites de una simple obra humana ${ }^{1}$.

Sin embargo, el catecismo surgido de la reforma católica, para contrarrestar los efectos de la reforma protestante, resulta sospechoso en ciertos puntos (afirmaciones o silencios), aunque a más de uno pueda sorprender.

Surgió con la finalidad expresa de que los párrocos tuvieran un libro, un manual de referencias, en el que pudieran encontrar la doctrina que debían enseñar al pueblo. En el libro mismo no se declara el nivel de profunda ignorancia en que estaba sumido el clero en ese momento de la historia. Cierto que hubo grandes lumbreras y excelentes aportaciones en el terreno de la catequesis antes y después de Trento; pero no es menos cierta la postración del clero: no hay más que consultar los lamentos de Felipe de Meneses, de Martín Lutero, de Roberto Bellarmino, de Juan de Ávila,...

Valgan las palabras dolidas de éste como testimonio fidedigno:

${ }^{1}$ No estoy seguro de que se haya afirmado que el de Trento era una obra «sobrenatural»; al menos no recuerdo ningún elogio en este sentido. Pero sí recuerdo perfectamente (año 1993, a raíz de la publicación del Catecismo de la Iglesia Católica), a alguna persona que me ha manifestado con desasosiego que no entendía que tuviera fallos, porque le habían asegurado que era «un catecismo inspirado» (textualmente). 


\begin{abstract}
«Y la suma verdad, que es Dios, (...) afirma haber venido todo este mal por no haber pastor que hubiese curado y cuidado lo que tocaba a la necesidad y provecho de sus ovejas. Mas, ¿por qué se les pide a estos pastores lo que no tienen? ¿Cómo ejercitar oficios de médicos, pues nunca aprendieron el arte? ¿Cómo aprenderán lo que no quisieron saber? Y ¿cómo han de saber lo que no tienen por necesario para el buen uso de su oficio?» ${ }^{2}$.
\end{abstract}

En el ambiente de la celebración del concilio de Trento que lo pidió, y en el inmediato posconcilio en que se elaboró y editó, podría dar la impresión que la enseñanza de sus páginas no acudía a remediar una necesidad urgente, sino a proporcionar un vademécum que estaba a salvo de toda duda. Lo cierto es que esta segunda intención expresa disimulaba las carencias y lagunas en que se movía la cristiandad, no confesadas. En ningún pasaje de la introducción aparece la palabra «ignorancia», pero sí consta, en cambio, la voluntad de atajar los errores del momento: es una maniobra hábil para echar las culpas a los adversarios ${ }^{3}$, sin pararse a reconocer la propia culpa ni las enormes carencias.

De hecho hay una característica en él que vale la pena resaltar, ya que no es por ahí por donde aparece su punto flaco. Esta nota es que deja a un lado todas las cuestiones de escuelas teológicas, para presentar la doctrina católica de la manera más objetiva posible, a fin de suscitar la mayor unanimidad, y promover la unión de voluntades, en lugar de dar pie a que surgieran disputas teológicas. Además, en sus páginas iniciales no se presenta como una cura de urgencia, sino como un medio de contrarrestar la influencia de la reforma, al hacer referencia a los múltiples libros que han editados los herejes sirviéndose del valioso invento de la imprenta, a fin de difundir sus ideas ${ }^{5}$. Con el catecismo se pretende ami-

${ }^{2}$ JuAn de Ávila, Memorial segundo al Concilio de Trento (1561), en L. Sala - F. Martín, San Juan de Ávila. Obras completas, Madrid, BAC, 2001, v. 2, 530.

${ }^{3}$ [Es necesario] «en estos tiempos (...) porque se han presentado en el mundo falsos profetas». (Catecismo de Trento, Introducción).

${ }^{4}$ [Para que] «los párrocos puedan sacar reglas ciertas para instruir a los fieles». (Catecismo de Trento, Introducción).

${ }^{5}$ «Nam praeter illa ingentia volumina quibus catholicam fidem evertere conati sunt, a quibus tamen cavere, cum apertam haeresim continerent, non magni fortasse laboris ac diligentiae fuit, infinitos etiam libellos conscripserunt, qui, cum pietatis speciem prae se fer 
norar la influencia de tales impresos, por medio de la difusión de la recta doctrina católica, que habían de dar a conocer los sacerdotes cuando tuvieran el libro en sus manos. De ahí las otras disposiciones sobre la enseñanza al pueblo cristiano, a la que están obligados obispos y párrocos, para que no se quede encerrada en las páginas de un libro 6 .

Durante los cuatro siglos que ha estado en uso, ha habido notables altibajos en su apreciación, en su empleo, o en la estima práctica que los católicos han hecho de él. De hecho, en tiempo de Clemente XIII, éste publicó la bula In dominico agro (14 de junio de 1761), con la finalidad de relanzar el empleo de un texto que había sido prácticamente dejado de utilizarse de manera general? Pero en los momentos de mayor aprecio, siempre fue tenido por un texto doctrinalmente seguro.

¿De dónde, pues, que se trate de un catecismo sospechoso? Las complicaciones vienen por varios conductos, y será mejor abordarlas una a una.

\section{Una engorrosa omisión involuntaria}

¿A quién no se le ha pasado alguna vez algún dato, una fecha, una frase,...? Las cosas no van por ahí, puesto que en estos casos se trataría simplemente de una errata, o de un simple error que no tiene mayor importancia. Pero un catecismo que pretendía liderar la formación de los clérigos, y que fue revisado y pulido, parece que tendría que ser publicado sin fallos. Aunque como toda obra humana, es falible.

En la nunciatura del Sacro Imperio, el nuncio en Polonia Giovanni Andrea Caligari escribió a finales de 1585 al Secretario de Estado para

rent, incredibile est quam facile incautos simplicium animos deceperint» ( = Además de los grandes libros con los que han tratado de adulterar la fe católica, de los que fue fácil guardarse sin demasiado esfuerzo y diligencia, pues contienen herejías nítidas, también escribieron una infinidad de pequeños libritos, que parecen libros piadosos, con los que ha sido tremendamente fácil seducir las mentes incautas de los más simples». (Catecismo de Trento, Introducción).

${ }^{6}$ CONCILIUM TRIDENTINUM, s, 24, de reformatione, c. 7: «Ut fidelis populus...», donde se señalan las obligaciones particulares, entre las que figura la de dirigirse al pueblo en lengua vulgar.

${ }^{7}$ L. Resines, La catequesis en España. Historia y textos, Madrid, BAC, 1997, 413. 
comunicarle, que mientras había estado al frente de la diócesis de Bertinoro (1579-1581), en Italia, había tratado de explicar el catecismo romano a sus curas. Y que entonces cayó en la cuenta de una omisión a propósito de la liturgia bautismal: «no se hacía mención del Óleo santo de los Catecúmenos». Era un silencio de índole litúrgica, aunque no doctrinal. Comunicaba que se lo había hecho saber a Guillermo Sirleto, principal redactor, unos años antes, cuando descubrió el fallo y aún vivía Sirleto (murió el 5 de octubre de 1585). Éste le respondió con cierta calma, señalando que se podría redactar un breve texto para insertarlo en su lugar correspondiente en ediciones sucesivas, y que no se diera más importancia, pasando el «arreglo» de puntillas ${ }^{8}$. Pero Sirleto debía consultar en este punto al papa, y no se llevó a cabo nada. Muerto Sirleto, Caligari volvió a insistir a Roma, preocupado no tanto por la integridad absoluta de los más mínimos detalles, cuanto por el hecho de no dar pie a que los protestantes aprovecharan el resquicio para arremeter contra los católicos, pues éstos exigían el empleo de los óleos, salvo en el caso de bautismo de urgencia, mientras que el catecismo oficial no lo señalaba: «Porque habiendo descuidado nosotros hablar de este Óleo santo en este libro donde se exponen cuidadosamente -junto al resto de la doctrina- todos los santísimos Sacramentos, los herejes se encargarán de decir a las gentes que nosotros pensamos como ellos y que estamos de acuerdo con su perversa opinión, alegando contra nosotros nuestro mismo Catecismo Romano» (Ibid., 52).

Pues bien, a pesar de la leal advertencia de Caligari (se le contestó: «Si pensarà»), hubieron de pasar 200 años para que la edición oficial de $1761^{9}$ incorporara un añadido -por descontado, sin advertir nada- para

${ }^{8}$ «Se podría arreglar el asunto preparando un breve texto sobre el tema para insertarlo en el lugar oportuno y hacerlo después imprimir con los mismos caracteres y distribuir el Catecismo con este añadido y sin decir palabra de la operación (con ogni secretezza)» Ver P. RodrígueZ, El Catecismo Romano ante Felipe II y la Inquisición española, Madrid, Rialp, 1998, 51.

${ }^{9}$ La adición aparece tanto en la edición llamada «clementina», oficial, por proponerla el papa Clemente XIII, publicada en Roma, 1761, como en la edición cuasioficial de Turín, apud Typographiam Regiam, 1761. (Ver: P. RodRíguez [ed.], Catechismus romanus seu Catechismus ex decreto Concili Tridentini ad parochos Pii Quinti pont. Max. iussu editus. Editio critica, Roma / Pamplona, Librería Editrice Vaticana / Ediciones Universidad de Navarra, 1989, 215. 
suplir la omisión ${ }^{10}$. Parece, pues, que esta práctica de añadir después sin advertir de nada, a la chita callando, es una vieja costumbre romana que ha perdurado hasta nuestros días.

\section{Una engorrosa omisión voluntaria}

Si lo que se refiere al apartado anterior fue un olvido involuntario, detectado en los primeros veinte años de vigencia del catecismo (parece que nadie lo detectó antes durante dos decenas), y subsanado tiempo después, el otro asunto es justamente inverso.

Se trata de una frase que fue voluntariamente omitida, a pesar de que formó parte del texto publicado. ¿Por qué se incluyó en la redacción?, ¿por qué se hizo desaparecer inmediatamente después? Extraños manejos que evidencian arrepentimientos o falta de seguridad.

Se trata de una frase que figuraba al exponer la cuestión de los efectos de la confirmación. El párrafo completo decía: «Itaque pastores docebunt confirmationem hoc cum ceteris sacramentis commune habere, ut, nisi impedimentum aliquod ex parte eius qui recipit, inferatur, novam gratiam tribuat. Etenim haec sacra et mystica signa eiusmodi esse demonstratum est, quae gratiam declarant atque efficiunt. Ex quo sequitur ut peccata etiam condonet ac remittat, quoniam gratiam simul cum peccato ne fingere quidem nobis licet» ( $=$ «Por consiguiente, los pastores enseñen que este sacramento de la confirmación tiene esto en común con los otros, que, si no existe impedimento por parte de quien lo recibe, da una nueva gracia. Pues está demostrado que éstos son señales sagradas y místicas que expresan la gracia y la realizan. De lo cual se sigue que también condona y

\footnotetext{
${ }^{10} \mathrm{El}$ inciso añadido dice en versión castellana: «Después ungen al que ha de ser bautizado en el pecho y entre las espaldas con el óleo de los Catecúmenos. En el pecho para que por el don del Espíritu Santo deseche el error y la ignorancia y abrace la verdadera fe: Pues el justo vive por la fe, y entre las espaldas para que por la gracia del Espíritu Santo sacuda de sí la pereza y entorpecimiento y se exercite en obras de virtud: Porque la fe sin obras está muerta». (Parte II, cap. II, n. 69). Citado por la edición de Madrid, Ramón Ruiz, 1791, 114. La edición latina de Madrid, Vda. de Pedro Marín, 1791, incluye una nota a pie de página que acota la adición, indicando que lamentablemente se echa en falta en casi todas las ediciones («Perperam desiderantur in omnibus fere editionibus»).
} 
perdona los pecados, pues la gracia no puede estar en nosotros unida al pecado» $)^{11}$.

No es fácil explicar la razón por la cual lo que aparece en cursiva fuera omitido en casi todas las ediciones, salvo en la primera. De hecho no resulta demasiado conocido que de la que llamamos primera edición del catecismo tridentino hubo dos ediciones, que se llevaron a cabo en la misma imprenta, de Paulo Manuzio, en 1566, una en folio, y otra en $8^{\circ}$. Además, como se verá a continuación, da la impresión de que la estrictamente primera es la de formato in- $8^{\circ}$, a la que siguió la otra in-folio. La verificación de este desajuste está documentada así:

«La edición in-8 de 1566 agrega: “Ex quo sequitur ut peccata etiam condonet ac remittat, quoniam gratiam simul cum peccato ne fingere quidem nobis licet”. Esta frase pertenece en exclusiva a la citada edición: está ausente tanto del ejemplar in-folio como de los subsiguientes in- $8^{\circ}$. No hemos encontrado un caso paralelo en este patrimonio textual. La misma composición tipográfica de la página correspondiente de esas ediciones posteriores muestra una explícita voluntad de eliminar ese inciso» ${ }^{12}$.

Hay, por tanto, voluntad clara y eficaz de suprimir esa frase, según la cual, el propio sacramento de la confirmación daba la gracia a quien lo recibía y eliminaba el pecado, porque gracia y pecado no podían subsistir juntos. Se propone una enseñanza, que, con el libro ya publicado, es eliminada precipitadamente, porque dejaba a un lado la importancia del sacramento de la penitencia. La omisión ha sido observada también por M. Catto, quien apunta con fina ironía: «frase che non compariva nelle edizioni succesive e che sembra una dimenticanza dallo squisito sapore volontario» ${ }^{13}$.

${ }^{11}$ P. Rodríguez (ed.), Catechismus romanus seu Catechismus ex decreto concilii Tridentini ad parochos Pii Quinti Pont. Max. iussu editus, Roma/ Pamplona, Librería Editrice Vaticana/ Ed. Univ. Navarra, 1989, 231.

${ }^{12}$ P. Rodríguez-R. Lanzetti, El Catecismo Romano: fuentes e historia del texto y de la redacción, Pamplona. Universidad de Navarra, 1982, 215-216. «... en los primeros meses de 1567 van a aparecer en varias ciudades europeas ediciones del Catecismo Romano impresas siempre -excepto la parisina de Kerver- sobre el ejemplar manuciano in- $8^{\circ}$, y no sobre la edición in-folio: tienen todas, en efecto, el inciso "ex quo..."”. 54.

${ }^{13}$ M. CATTO, Un panopticon catechistico, Roma, Edizioni di Storia e Letteratura, 2003, 
Más adelante, posiblemente a partir de la edición llamada «clementina» (1761), se incorporó el inciso suprimido, al que apenas se le dio importancia pese a que planteaba una especie de confrontación entre sacramentos $^{14}$.

\section{Fracaso de la edición latina en España}

Editado por primera vez en Roma, Paulo Manuzio, 1566 (en la doble edición ya consignada), el papa Pío V concedió el privilegio al impresor, como solía ser habitual. Pronto, sin embargo, se sintió la demanda de ejemplares en diversos países, especialmente porque se trataba del libro al que podían acudir los teólogos para encontrar la síntesis posconciliar de la doctrina católica, y contrarrestar la influencia protestante. Los pocos ejemplares que llegaron a España provocaron una reunión del nuncio con representantes de los cabildos españoles; en la misma estos representantes le elevaran la demanda de una edición a la que pudieran acceder fácilmente ${ }^{15}$. El nuncio, Juan Bautista Castagna (posteriormente papa Urbano VII), elevaron la petición a Roma, que dio facultad para imprimirlo, con la condición de que el texto fuese respetado y no se introdujeran corruptelas. Pío V deseaba la difusión, y no vio problemas en que se realizase una edición en España.

Pero tres teólogos españoles -se puede decir con toda verdad «más papistas que el papa»- vieron problemas en la doctrina sacramental. En esta segunda parte, el catecismo seguía las enseñanzas de santo Tomás de

${ }^{14}$ La edición mencionada de Madrid, Ramón Ruiz, 1791, 122, dice: «...Porque ya se demostró que estas sagradas y místicas señales causan la gracia que significan. De donde se sigue que perdone también y remita los pecados. Porque juntarse con el pecado la gracia, ni aun fingirlo podemos. Pero además de estos efectos...». La edición de Madrid, Gregorio del Amo, 1900 adjunta a este inciso una nota a pie de página que dice: «Clem. p. e ad Julium; Melch., papa in ep. ad episcopos Hispan.».

${ }^{15}$ Un ejemplar que llegó a España con seguridad fue a parar a las manos del agustino Alonso de Orozco, quien en su Cathecismo prouechoso. Hecho por el Padre Fray Alonso de Orozco, predicador de su M. En el qual se declara solamente nuestra ley Christiana ser la verdadera. Y todas las otras sectas ser engaños del demonio, Zaragoza, Iuan Millán, 1568, hace en tres momentos alusión al catecismo de Trento. (Ver L. Resines, A. de Orozco, Cathecismo prouechoso, en R. LAZCANO [ed.], Obras completas, I, Obras castellanas, Madrid, BAC, 2001, 705). 
Aquino en la Summa Theologica, a través de dos libros: los Comentarios de Domingo de Soto, y el Catecismo de Carranza, denostado por la Inquisición española pero favorablemente acogido por los padres conciliares. Mientras se gestionaba el proceso de edición, estos tres teólogos vieron problemas, que en este caso no eran de índole litúrgica, como ya había sucedido en la omisión reseñada antes, sino de índole teológica. El nuncio Castagna informa a Roma de que

«algunos teólogos muy estimados en esta corte han calificado un pasaje del Catecismo como peligroso y malsonante, $\mathrm{o}$ al menos que puede ser mal interpretado» ${ }^{16}$.

Los tres teólogos eran el Dr. Hernando de Barriovero (también llamado en ocasiones «Barrionuevo»), magistral de Toledo; el dominico Diego de Chaves, y el jerónimo Francisco Villalba. Y el pasaje al que ponían reparos teológicos versaba sobre la necesidad de que todos accedieran al bautismo para obtener la salvación. El pasaje se encuentra en el Catecismo, parte II, cap II, n. 21:

«... desde ese tiempo [desde Cristo] empezaron a ser obligados por la ley del Bautismo todos los hombres que habían de conseguir la vida eterna» ${ }^{17}$.

Parece deducirse de la literalidad de la expresión que los que habían de conseguir la vida eterna necesitaban bautizarse, mientras que los que no la habían de conseguir (predestinación) no estaban obligados a recibir el sacramento. Se debatía, pues, la absoluta necesidad de medio por la que todos debían recibir el bautismo, se salvaran o condenaran; o la simple necesidad de precepto, por la que sería necesario únicamente para los conocieran la voluntad de Cristo.

En reunión habida con el nuncio Castagna, uno de los tres teólogos, Francisco Villalba proponía introducir una modificación en el texto del catecismo que había sido aprobado por la comisión posconciliar y refren-

${ }^{16}$ P. RodríGuez, El Catecismo Romano..., 29 y 42.

${ }^{17}$ Citado por el edición de Madrid, Vda. de Pedro Marín, 1791. El texto latino dice: «Ex eo tempore, omnes homines qui salutem aeternam consecuturi erant, lege de baptismo teneri coepisse». 
dado por la autoridad papal; la sugerencia era que la frase qui salutem aeternam consecuturi erant (= los que habían de conseguir la salvación eterna) debía modificarse: bien suprimiéndola totalmente (el texto quedaría: «ex eo tempore, omnes homines lege de baptismo teneri coepisse»), bien sustituyéndola por ut vitam possint consequi aeternam (= los que habían de conseguir la salvación eterna); con esta redacción resultaría: «ex eo tempore, omnes homines ut vitam possint consequi aeternam, lege de baptismo teneri coepisse».

En tal reunión entre el nuncio Castagna y los tres teólogos, hubo un clima sereno y de aceptación de propuestas; no hubo posturas rígidas e inflexibles, y llegaron a la conclusión de que el Catecismo, tal como estaba redactado, afirmaba la necesidad del bautismo, pero no de un modo exclusivo.

La propuesta fue cursada por el nuncio a Roma, por el mismo tiempo en que el papa había encomendado al nuncio la responsabilidad de llevar adelante una edición latina española. El nuncio tenía conocimiento de que en la corte española de Felipe II los teólogos (y más si estaban vinculados con la Inquisición) tenían mucho peso, por lo que intuyó que la proyectada edición española tropezaría con dificultades para sacar adelante este párrafo. Pero tampoco era lógico que las otras ediciones latinas o bilingües que se hacían por aquellos días en el extranjero tuvieran una redacción, mientras que la española presentara otra redacción diferente («Spain is different»). Su comunicación a Roma da a entender las dificultades previstas:

«He querido dar aviso de todo este asunto a Su Santidad antes de que se imprima [la edición española], porque bien podría suceder que esta opinión empezase a adquirir tanto peso en la corte que no se autorizase la edición si no es prescindiendo de las palabras censuradas» ${ }^{18}$.

En Roma cayó mal la propuesta española, que hurgaba en los entresijos de la afirmación y detectaba un posible sentido erróneo («peligrosa, mal sonante, $\mathrm{o}$, al menos, que se prestaba a mala interpretación»). Ningún

\footnotetext{
${ }^{18}$ «Ho voluto darne avisa a Sua Santita avanti che s'imprima, perche potria essere che questa opinione andassi qui tanto avanti che non lasciassero imprimerlo se non levando quelle parole» en P. RodríGueZ, El Catecismo Romano..., 48 y 184-185.
} 
otro teólogo católico de ningún otro país había sospechado las desviaciones que conjeturaban los españoles; nadie había tenido la osadía de proponer una supresión o una modificación. Desde la curia romana reprocharon a los españoles que en lugar de acatar y aceptar el texto se dedicaran a criticarlo sin necesidad. La respuesta romana (19 de julio de 1567), tajante, cerró el asunto con un seco: «Ma di questo, basti» (Ya está bien en este asunto ${ }^{19}$. Hay que recordar que el papa Pío V había mandado al nuncio que se llevara a cabo la edición latina en España, pero manteniendo el texto sin alteraciones.

En consecuencia, la edición latina que se iba a publicar en España, ante el riesgo de que no respetara el texto por intromisión de las presiones de la corte, a sugerencia de unos teólogos, quedó definitivamente paralizada. Se aseguró que desde Italia se suministrarían abundantes ejemplares no alterados para atender la demanda. Pero no hubo edición oficial española.

Hubieron de pasar diez años para que, en edición privada, llevada a cabo en Medina del Campo por el mercader Benito Boyer, 1577, se publicara en latín el catecismo romano para uso de aquéllos que desearan acceder a su texto ${ }^{20}$.

\section{La traducción que nunca se publicó}

Junto a la recomendación de hacer una edición latina para España, encargada al nuncio Juan Bautista Castagna, estaba también la de una traducción oficial. La edición latina constituyó un estrepitoso fracaso debido a las puntillosas salvedades de algunos teólogos españoles. La posibilidad de traducción siguió otros derroteros, pero terminó en el mismo paradero.

Luis de Requesens, embajador española ante Roma, envió una carta (junio de 1567) al Inquisidor General, Diego de Espinosa, según la cual, de resultas de su entrevista con Pío V, éste encomendaba (¿ordenaba?) que confiara a una persona experta y segura la traducción del Catecismo romano. Con ello, Pío V pretendía:

${ }^{19}$ P. Rodríguez, El Catecismo Romano..., 48-49 y 192.

${ }^{20}$ L. Resines, Los catecismos de Trento editados en Medina del Campo (1577-1604), en "Estudio Agustiniano" 47 (2012) 273-300. 
«que el Catecismo pueda ser entendido por todos, también por los que no tienen cultura latina; de esta manera, mejorará la formación católica de sus súbditos y se fomentará en ellos una mejor observancia de los decretos del Concilio».

El breve pontificio (25 de mayo de 1567) que encomienda semejante tarea al Inquisidor General, -a la vez presidente del Consejo de Castilla-, señala que la proyectada traducción española se ajuste al modelo de la traducción italiana. Teóricamente Felipe II era quien «solicitaba» el favor al Papa; éste «concedía» graciosamente lo solicitado. Dicho breve encargaba la traducción e implícitamente daba licencia pontificia para imprimir, a pesar de la prerrogativa exclusiva de que disponía Aldo Manuzio para Italia.

Precisamente por ello, Requesens entendió que se precisaba autorización explícita para imprimir, a diferencia de lo que había sucedido en Francia, Alemania o Polonia, en que las traducciones respectivas surgen como iniciativa papal, a fin de contrarrestar el pensamiento protestante, mucho más activo que en España. Este encargo de traducción hecho al Inquisidor Diego de Espinosa es simultáneo al encargo de edición latina, encomendado al nuncio Juan Bautista Castagna.

Diego de Espinosa encargó la traducción a Pedro de Fuentidueña, canónigo de Salamanca; el 17 de julio de 1570 hay constancia de tal encargo, aunque en realidad se produjo bastante antes, y el nuncio se refiere al asunto como un hecho previo. El encargo de traducción debió llevarse a cabo no demasiado tiempo después de que Espinosa recibiera el breve pontificio que se lo encomendaba (por tanto, en 1567). La traducción de un texto extenso, y los matices que era preciso salvar llevaron cierto tiempo. Lo seguro es que en enero de 1570 Fuentidueña tenía la traducción concluida, y se encaminó de Salamanca a Madrid, a fin de hacérsela llegar al Inquisidor.

Éste, por obligación de su cargo, tenía que acompañar al monarca en su desplazamiento a Córdoba. Delegó el examen de lo que presentaba la traducción en su hombre de confianza, Diego de Chaves, dominico, uno de los tres que había detectado inexactitudes en el texto latino sobre el bautismo. Entre enero y mitad de febrero del mismo 1570, Diego de Chaves examinó el texto traducido; hizo algunas observaciones respecto a la 
versión al autor de la misma, Fuentidueña, quien las aceptó gustoso. El 14 de febrero de 1570, Diego de Chaves entregó su dictamen sobre el texto traducido que había examinado, y que estaba avalado, además, por el también dominico Juan de la Fuente.

Tal dictamen se para a analizar no sólo si la traducción es buena o mala, sino además se enreda en cuestiones como si procede o no llevarse a cabo cualquier traducción, dada la política que en este punto llevaba la Inquisición en España. En consonancia con este criterio, el dictamen estima que no es oportuno traducir el texto del catecismo, dados los tiempos que corren: «ni bien ni mal traducido conviene que ande en castellano». Poco importaba el deseo y el encargo expreso del papa a juicio de los inquisidores. Como el Inquisidor General estaba ausente, su dictamen fue examinado en Madrid por el Consejo de la Suprema, y se impuso el criterio restrictivo de Chaves. Quienes intervinieron y firmaron el acuerdo fueron los inquisidores Francisco de Soto, Fernando de la Vega y Juan de Ovando. Como era preceptivo, elevaron la propuesta al Inquisidor General con esta recomendación: que «el dicho catecismo no se imprima, por los muchos ynconbenientes que se podrían resultar» ${ }^{21}$.

De resultas de semejante propuesta, Diego de Espinosa se encontraba en una situación comprometida. Por un lado, el encargo papal de gestionar la traducción; por el otro, la recomendación del Consejo de la Suprema desaconsejando cualquier traducción, no porque fuera de buena o mala calidad la intervención de Fuentidueña como traductor, sino por sí misma. En tal dilema, Espinosa se entrevistó con Felipe II, y de tal entrevista salió un acuerdo: $1^{\circ}$.) Que el acuerdo del Consejo era digno de consideración; $2^{\circ}$.) Que examinarían el asunto con calma; $3^{\circ}$.) Que no era ya necesario que Fuentidueña continuara en Madrid. El asunto pasó a manos del rey, quien no quería desairar a Pío V (ya había habido conflictos con Pío IV). Pero de tal acuerdo nada se informó a Pío V. La táctica fue la de dar largas al tema, sin provocar tensiones.

Como la presencia de Fuentidueña ya no era necesaria, éste acudió a Roma, con otros asuntos del cabildo salmantino al que pertenecía. Pero no había forma de evitar que, estando presente en Roma, allí se supiese de su intervención en la traducción ya completada. Parece enteramente lógico que Fuentidueña lo comunicara, puesto que había estado en el Con-

${ }^{21}$ P. Rodríguez, El Catecismo Romano..., 115. 
cilio de Trento como teólogo del obispo de Salamanca, Pedro de Mendoza, y era conocido de otros conciliares, algunos de los cuales intervinieron en la redacción posconciliar del Catecismo. Hay que dar por supuesto que en las esferas de la curia romana se conocía que la traducción estaba disponible.

De ahí que no extraña que el 8 de octubre de 1571 -año y medio después de que Fuentidueña entregara su trabajo terminado- escribieron desde la Secretaria de Estado al nuncio Castagna, para lamentarse de la lentitud de una traducción que se difería inexplicablemente, a pesar del encargo pontificio. Pero en aquellas mismas fechas, importaba más otro asunto, como era coaligar a las potencias católicas (España, Portugal, Venecia,...) en la liga contra los turcos; y el asunto del catecismo quedó relegado a un segundo plano, como una cuestión que no requería tanta atención. En abril de 1572, Fuentidueña regresó a España, con lo que se difuminaba su voz (y su presencia) que podría recordar el asunto pendiente de la traducción ${ }^{22}$. El remate para este olvido, interesado por parte de la Inquisición española, lo puso la muerte de Pío V (1 de mayo de 1572); nadie volvió a urgir la traducción española.

Hasta 1777 no se efectuó una traducción española, en Pamplona, a cargo de Lorenzo Agustín de Manterola. En 1782, cuatro años después, se publicó otra versión española, realizada por Agustín Zorita, en esta ocasión en Madrid. Dos siglos en los que el catecismo solamente pudo ser consultado por los que disponían de conocimientos de latín, y estuvo vetado al resto.

La puntillosa Inquisición española no veía más que inconvenientes en que circulara en manos del pueblo, en lengua asequible, un texto que estaba destinado, en principio para los curas, pero que debía contribuir a la formación del pueblo fiel. El argumento de Diego de Chaves, retorcido, era que si el cura sabía latín, no precisaba la traducción; y que si no sabía latín, no convenía poner a su alcance el texto del catecismo.

${ }^{22}$ Existe un error en la apreciación que P. MARTín redactó en la «Introducción histórica» que precede a la edición del Catecismo Romano, Madrid, BAC, 1956, XLIX, nota 65, donde dice: «En España se encomienda la traducción española al Cardenal Espinosa; luego hizo otra el mismo Fuentidueña, pero surgen dificultades por el recelo que suponían los escritos teológicos en lengua vulgar, y se dejó por entonces de imprimir». No se trataba de dos traducciones, sino que Diego de Espinosa encomendó el encargo a Pedro de Fuentidueña. 
Esto se inscribe en la política de negarse a las traducciones de la Biblia al castellano; de no poner en manos del pueblo cosas que resultaban difíciles, o que podrían ser malentendidas; de evitar los inconvenientes que se habían producido en otros países al divulgar los asuntos de la religión; el que el texto del catecismo podría ser mal entendido y mal interpretado; que poner en manos del vulgo los misterios de la fe o las fórmulas sacramentales podría derivar en disputas irreparables.

Es decir, que frente a la voluntad y criterio del papa Pío V de dar a conocer la obra acordada en Trento, para formación del pueblo cristiano -directamente o indirectamente a través de los párrocos-, pudo más el restrictivo criterio inquisitorial que entreveía las más nefastas consecuencias. El sentido de una defensa a ultranza de la fe, con la medida preventiva de evitar la difusión del catecismo, terminó por imponerse al sentido de la obediencia a una decisión del concilio de Trento y del papa ejecutor del mismo.

La traducción encargada por vía oficial se difuminó en el tiempo, como la niebla ante el sol. En julio de 1567, con la sospecha de enseñanzas sospechosas en el catecismo, se puso fin a la posibilidad de edición latina para España. Entre 1570 y 1572, con la política de dar largas a los temas, y no agilizarlos, se enterró la traducción española bajo la losa de un silencio que encubría los recelos de los inquisidores respecto a una obra que veían no era recomendable anduviese en manos del pueblo.

\section{La traducción que se perdió}

Esta cuestión consiste en un nuevo intento de difundir en castellano el texto del catecismo romano. Es un conato totalmente independiente del anterior, el cual tenía carácter oficial, mientras que el que sigue tiene una iniciativa enteramente privada. Es claro, no obstante, que esto no la desautoriza por principio.

La iniciativa privada tiene una fecha conocida de salida a la palestra pública: el 7 de octubre de 1568 (por tanto, en simultaneidad con las otras gestiones examinadas) el doctor Cristóbal de Cabrera presentaba ante el Santo Oficio de Valladolid la traducción íntegra que él había llevado a cabo del catecismo romano, a fin de que fuese examinada, y se le diera li- 
cencia de impresión, es decir, que fuese supervisada para asegurar que era enteramente limpia y válida en cuanto a la expresión de la fe católica.

Cristóbal de Cabrera había nacido en Zaratán, junto a Valladolid, en $1513^{23}$. Pasó muy joven a México, donde adquirió una notable formación teológica, y fue ordenado sacerdote por el arzobispo de México, Juan de Zumárraga. Regresado a España en fecha no conocida, se vuelven a encontrar noticias suyas en 1545 como beneficiado de la colegial de Santa María, de Medina de Rioseco. Marchó a Roma en una primera estancia que se puede datar entre 1560 y 1561; en esa estancia conoció de primera mano los trabajos posconciliares y entabló amistad con Guillermo Sirleto, responsable último de la redacción del catecismo romano. La amistad se mantuvo a través de la correspondencia, cuando Cabrera regresó a Medina de Rioseco en 1564. De hecho Sirleto le envió uno de los ejemplares de la primera edición romana del catecismo. En su calmado retiro de Medina de Rioseco, su lectura serena le impresionó, y tomó la decisión de traducirlo, con el innegable propósito de dar a conocer y poner a disposición de otros lo que estimaba como un libro valioso. Entre finales de 1567 y 1568 llevó a cabo su traducción, que presentó al Santo Oficio de Valladolid el 7 de octubre de ese año. Las palabras de su prólogo son altamente expresivas de una limpia intención:

«Pueden por ventura decir algunos que se mueven más por la ambición del mundo que por la honra de Dios o provecho del próximo, que parece cosa indigna de hombre de mi edad y studio escribir esto en vulgar y traducirlo del Latín, poniéndolo todo tan llano y baxo con solo el trabaxo. A esto se responde que la charidad de Cristo, nuestro Salvador y maestro, y el exemplar que nos dexó desa admirable humildad, puesto por spejo delante de mis ojos, movió y dio a entender que me abaxava muy poquito en lo que sólo por amor y charidad del próximo me afficioné a hacer. Y en esta quenta se reciban mis obrecillas tales quales son» ${ }^{24}$.

${ }^{23}$ Según Bataillon, Erasmo y España, México, Fondo de Cultura Económica, 1966², 820, había nacido «en Burgos hacia 1515, murió en Roma en 1598, vivió el México a la sombra de Zumárraga y más tarde de Quiroga y tradujo en México los argumentos griegos de las epístolas según el Nuevo Testamento de Erasmo, que poseía Zumárraga».

${ }^{24}$ Citado por P. RodríGuez, El Catecismo Romano..., 95. 
Con cuanto antecede, y sabedores nosotros hoy -posiblemente él estaba ajeno a todo cuanto había sucedido en España- que el 14 de febrero de 1570 el consultor Diego de Chaves había dictaminado lo improcedente que resultaba una traducción al castellano, y que tal recomendación había sido refrendada por los miembros del Consejo de la Suprema, no resulta difícil intuir que año y medio antes, en octubre de 1568, estaban de plena actualidad los criterios de no dar al pueblo aquello que desbordaba su capacidad, y que podría malinterpretar.

Según la pragmática de 1558 sobre la impresión de libros, tendría que haberlo presentado en el Consejo de Castilla para solicitar licencia de impresión ${ }^{25}$. Pero al tratarse de un asunto religioso, era evidente que la Inquisición podía intervenir sobre el libro. Cristóbal de Cabrera quiso anticiparse para evitar posteriores sinsabores.

Ahora bien, la Inquisición de Valladolid envió un dictamen al Consejo Supremo en el que aconsejaba a sus miembros que:

«no se imprima esta traducción: es cosa peligrosa que ande en manos del bulgo y de gente simple lo que se hizo para ynstruir a los que han de enseñar al bulgo».

Conviene observar que en tal dictamen no se entra en la calidad de la traducción, si es o no ajustada a las criterios teológicos, o si hay frases que expresen la fe con poca justeza o de forma equívoca. Nada de eso. Pasando por encima de una valoración de la traducción, se centra con exclusividad en otro tema: es un serio inconveniente que un texto tan subido de tono ande en manos de la gente vulgar; se hizo para instruir a los párrocos; que sean ellos, por tanto, quienes lo manejen y enseñen al resto. Pero de ninguna manera se ponga directamente en manos de los seglares, ni siquiera de los que tuvieran una capacidad suficiente.

El criterio y la decisión final del Consejo Supremo fue que no procedía la traducción, asumiendo la recomendación que procedía de Vallado-

${ }^{25}$ [Pragmática]. Sobre la impresión y libros. La orden que se ha de tener en imprimir los libros ansí los impresores, como los que los dan a imprimir. $Y$ ansi mesmo los libreros en la forma que los han de vender, y las diligencias que los unos y los otros son obligados a hazer, juntamente con la orden que se ha de tener en visitar las librerías ansí de los libreros como de otra cualesquier personas, ansí ecclesiásticas como seglares. Con privilegio, Tassado a cinco maravedis el pliego, Valladolid, Sebastián Martínez, 1558. 
lid, pero con la que comulgaban plenamente; por consiguiente, procedía únicamente devolver el manuscrito a Cabrera.

Sin embargo, no se produjo la devolución, y el manuscrito permaneció en la trastienda. No se iba a editar, pero parecía que tampoco se iba a devolver. Nada dijeron a Cristóbal de Cabrera, ni se comprometieron -a favor o en contra- con su traducción. Cristóbal de Cabrera estuvo en Medina de Rioseco hasta principios de 1572, en que marchó de nuevo a Roma, de donde ya no regresaría ${ }^{26}$. Pero reclamó su manuscrito en 1572 , en 1584, y en 1593. Infructuosamente. Por las fechas de 1572, Diego de Espinosa tenía el encargo de la traducción oficial (desde el 25 de mayo de 1567); había encomendado a Pedro de Fuentidueña la traducción de la que él era responsable. Ahora bien, inopinadamente, un año después de recibir el encargo, llegaba a sus manos una traducción completa del catecismo, a finales de 1568. No pasaba nada si se dejaba correr el tiempo, y, tal como rodaran las cosas, existía la posibilidad de echar mano de ella si fuera preciso, para dar por satisfecho el encargo que se había puesto en sus manos. En caso de que Fuentidueña no pudiera ejecutarlo por cualquier motivo, siempre sería una forma airosa de quedar bien. No obstante, prevalecía el criterio de que era preferible hurtar esas cosas a la lectura de la gente sin preparación.

Cristóbal de Cabrera, ya anciano, reclamó inútilmente desde Roma su manuscrito. Pero éste ni le fue devuelto, ni utilizado, ni publicado.

La iniciativa de Pío V, deseoso que el catecismo que había mandado publicar se difundiese por el orbe cristiano, se estrelló una y otra vez en España. En una ocasión porque los teólogos españoles, puntillosos, vieron inexactitudes que hacían desaconsejable la publicación latina del texto oficial. En otra ocasión, porque la posibilidad de edición castellana, impresa en España para atender la demanda de conocimiento, fue torpedeada, ya que la corte española, sustentada por la Inquisición, no vería con buenos ojos la publicación de un libro que había suscitado recelos; la voluntad papal cedía ante el juicio político de la tranquilidad religiosa del reino. Por tercera ocasión, ante una leal aportación de una traducción que espontáneamente se brindaba a ser difundida, pues los mismos criterios

${ }^{26}$ Cabrera es autor de: Scuela de la doctrina y disciplina christiana provechosa a todo fiel christiano, ms., 1567. Tal manuscrito, junto a otras obras, se encuentran en los fondos vaticanos. 
restrictivos veían con desconfianza que fuera buena cosa poner la teología en manos del pueblo. La lección es un tanto desoladora.

Si a ello se añade que, con anterioridad, se había detectado un fallo litúrgico en las enseñanzas del catecismo romano, y que éste no se había subsanado hasta dos siglos después, se puede entender, sin problemas, que el célebre catecismo sea puesto en la picota, expuesto a la pública vergüenza.

A pesar de que siempre existan nostálgicos que añoren que lo de antes fue siempre mejor, no hay más remedio que reconocer que el texto del catecismo acusa los efectos del tiempo pasado. Si lo que ha aparecido hasta ahora son notas sobre su contenido y sobre la historia que gira en torno al texto tridentino, no se completaría el panorama actual si no se contemplara con ojos del presente, para examinar su enseñanza. Hay una sustancia cristiana fundamental, que no ha variado con el tiempo, aunque se hayan modificado los criterios de expresarla. Pero, además, hay una serie de disposiciones disciplinares, o de formas de pensar que se deslizan de forma inevitable, como algo natural, que no están ligadas con la esencia de la fe, que han variado de manera muy notable. Es todo cuanto se refiere a los signos de los tiempos. Y los tiempos de hoy no son los mismos que los del siglo XVI que le vio nacer.

Sería tarea demasiado ardua ir señalando al detalle las múltiples variaciones que habría que introducir, si se quisiera llevar a cabo la actualización de este catecismo. Se tardaría menos si se hiciera otro catecismo distinto. Pero vale la pena proponer un par de ejemplos de la escasa acomodación a nuestro tiempo. Los nostálgicos que aún lo siguen buscando y estudiando deberían ser un poco más cautos, o un poco más estudiosos. Y sobre todo, deberían haber caído en la cuenta que lo esencial de la fe cristiana no se encuentra en el catecismo de Trento, sino en el evangelio.

El primer ejemplo elegido de la falta de sintonía con los criterios actuales se encuentra en la parte II, capítulo II, número 25. Trata de quiénes pueden llevar a cabo el bautismo de urgencia (antes ha señalado que también pueden realizarlo los judíos, los infieles y los herejes). Pero establece un orden jerárquico para que los fieles no crean que se ha concedido esta potestad indiscriminadamente ( $=$ «Neque vero hoc munus ita ómnibus promiscue permissum esse fideles arbitrantur»). El texto señala un orden de categoría, de mayor a menor, y el último lugar lo ocupa la mujer. Hasta ahí, no resulta demasiado llamativo. Pero señala una excepción, pues 
frente a un hombre menos preparado o más dubitativo, es preferible que intervenga la partera. Con mayor experienciaprofesional, puede llevarlo a cabo mejor. Lo que resulta increíble al pensamiento actual es la razón que ofrece el texto para sostener que esto es una excepción: «quod alias viri magis proprium officium videretur» (= lo cual además ha de considerarse oficio más propio del varón). ¿Jesús de Nazaret dijo algo al respecto?, ¿no será que hemos introducido nuestros criterios humanos, falibles, haciéndolos pasar por inmutables por alguna misteriosa razón?

El otro ejemplo elegido también forma parte de la práctica sacramental, y se localiza en la parte II, capítulo VIII, número 34. Ahí se enseña como principio general que para obtener bienes de Dios han de acompañarse de santas disposiciones o súplicas (sacris precationibus). Una de estas santas prácticas es la abstención temporal de la unión matrimonial (= «Matrimonii officio interdum abstineant»); por consiguiente, de esta proposición se deduce su contraria: que el uso del matrimonio es una acción no santa (¿pecaminosa?). Como es lógico, la abstención ha de llevarse a cabo por alguna razón de peso, no arbitrariamente; y una razón que lo justifica es «tribus saltem diebus antequam sacram eucharistiam percipiant» (= al menos tres días antes de que comulguen).

No creo que en la actualidad esto pueda enseñarse sin provocar reacciones extremas. No vieron problemas en esto los inquisidores españoles del XVI cuando hilaban tan fino. Ni percibieron problemas al traducirlo, en las traducciones que no debían llegar al pueblo inculto. Todo lo contrario, se afirma en este apartado que conviene enseñarlo así a los fieles.

Hay otros cuantos puntos que resultan difíciles de sostener o de enseñar en la actualidad. Valgan estos ejemplos, pero, por unas u otras razones, el texto pretendidamente perfecto, exquisito, libre de toda clase de defectos, fue de tumbo en tumbo, dando en España más traspiés que en ninguna otra parte del orbe católico. 